\title{
Developmental dynamics of voltage-gated sodium channel isoform expression in the human and mouse neocortex
}

Lindsay Liang ${ }^{1}$, Siavash Fazel Darbandi ${ }^{1}$, Sirisha Pochareddy ${ }^{2}$, Forrest O. Gulden ${ }^{2}$, Michael C. Gilson $^{1}$, Brooke K. Sheppard ${ }^{1}$, Atehsa Sahagun ${ }^{3}$, Joon-Yong An ${ }^{4}$, Donna M. Werling ${ }^{5}$, John L.R. Rubenstein $^{1}$, Nenad Šestan $2,6,7,8,9$, Kevin J. Bender ${ }^{3}$, and Stephan J. Sanders ${ }^{1,10,11,+}$

${ }^{1}$ Department of Psychiatry and Behavioral Sciences, University of California, San Francisco, San Francisco, CA 94158.

10 2Department of Neuroscience and Kavli Institute for Neuroscience, Yale School of Medicine, 11 New Haven, CT 06510, USA.

$12{ }^{3}$ Department of Neurology, University of California, San Francisco, San Francisco, CA 94158, 13 USA.

$14{ }^{4}$ School of Biosystem and Biomedical Science, College of Health Science, Korea University, 15 Seoul, 02841, Republic of Korea.

16 5Laboratory of Genetics, University of Wisconsin-Madison, Madison, WI 53706, USA.

17 ' $P$ rogram in Cellular Neuroscience, Neurodegeneration, and Repair and Yale Child Study Center, 18 Yale School of Medicine, New Haven, CT 06510, USA.

$19{ }^{7}$ Department of Psychiatry, Yale University School of Medicine, New Haven, CT 06520, USA.

$20{ }^{8}$ Department of Genetics, Yale University School of Medicine, New Haven, CT 06520, USA.

$21{ }^{9}$ Department of Comparative Medicine, Program in Integrative Cell Signaling and Neurobiology

22 of Metabolism, Yale School of Medicine, New Haven, CT 06510, USA.

$23{ }^{10}$ Institute for Human Genetics, University of California, San Francisco, San Francisco, CA 94158, 24 USA.

$25{ }^{11}$ Bakar Computational Health Sciences Institute, University of California, San Francisco, San

26 Francisco, CA 94158, USA.

28 †Please address correspondence to: stephan.sanders@ucsf.edu (S.J.S.)

29 


\section{Abstract}

Objective: Genetic variants in the voltage-gated sodium channels SCN1A, SCN2A, SCN3A, and $S C N 8 A$ are leading causes of epilepsy, developmental delay, and autism spectrum disorder. The mRNA splicing patterns of all four genes vary across development in the rodent brain, including mutually exclusive copies of the fifth protein-coding exon detected in the neonate $(5 \mathrm{~N})$ and adult (5A). A second pair of mutually exclusive exons is reported in SCN8A only (18N and 18A). We aimed to quantify the expression of individual exons in the developing human neocortex. Methods: RNA-seq data from 176 human dorsolateral prefrontal cortex samples across development were analyzed to estimate exon-level expression. Developmental changes in exon utilization were validated by assessing intron splicing. Exon expression was also estimated in RNA-seq data from 58 developing mouse neocortical samples.

43 Results: In the mature human neocortex, exon $5 \mathrm{~A}$ is consistently expressed at least 4-fold

44 higher than exon $5 \mathrm{~N}$ in all four genes. For SCN2A, SCN3A, and SCN8A a synchronized 5N/5A transition occurs between 24 post-conceptual weeks ( $2^{\text {nd }}$ trimester) and six years of age. In mice, the equivalent 5N/5A transition begins at or before embryonic day 15.5. In SCN8A, over $90 \%$ of transcripts in the mature human cortex include exon $18 \mathrm{~A}$. Early in fetal development, most transcripts include $18 \mathrm{~N}$ or skip both $18 \mathrm{~N}$ and $18 \mathrm{~A}$, with a transition to $18 \mathrm{~A}$ inclusion occurring from 13 post-conceptual weeks to 6 months of age. No other protein-coding exons showed comparably dynamic developmental trajectories.

51 Significance: Splice isoforms, which alter the biophysical properties of the encoded channels, 52 may account for some of the observed phenotypic differences across development and

53 between specific variants. Manipulation of the proportion of splicing isoforms at appropriate stages of development may act as a therapeutic strategy for specific mutations or even epilepsy

55 in general.

\section{Keywords}

58 isoform, splicing, epilepsy, neurodevelopmental disorders, SCN1A, SCN2A, SCN3A, SCN8A, 5A, 


\section{Introduction}

Genetic variation in the genes SCN1A, SCN2A, SCN3A, and SCN8A are a major cause of epileptic encephalopathy (EE), autism spectrum disorder (ASD), and developmental delay. ${ }^{1-3}$ These four homologous genes encode voltage-gated sodium channels (Nav1.1, Nav1.2, Nav1.3, and Nav1.6 respectively) that are critical for a range of functions in the central nervous system, ${ }^{4}$ including axonal action potential initiation and propagation, ${ }^{5,6}$ dendritic excitability, ${ }^{7,8}$ macroscopic anatomical development, ${ }^{9}$ and activity-dependent myelination. ${ }^{10}$ The functional role, subcellular location, expression-level, and isoform selection of voltage-gated sodium channels vary across development and understanding this relationship is critical for understanding the etiology of the associated disorders and their therapeutic management.,11-19 While some isoform-level differences have been assayed in rodents and mature human brains, ${ }^{20-22}$ the trajectories in the developing human cortex have not been described. ${ }^{23}$

Sodium channel genes are composed of multiple exons, which can be protein-coding (CDS for CoDing Sequence), untranslated regions (UTRs), or non-coding exons (NCEs). Differing combinations of these exons are called isoforms, which can change the amino acid sequence of the encoded proteins (proteoforms). The best-characterized isoform change across these four sodium channels are the two mutually exclusive copies of the fifth protein-coding exon. ${ }^{17,24}$ This exon encodes part of the first domain of the Nav channel, including the end of transmembrane segment S3, most of transmembrane segment S4, and a short extracellular linker connecting these two segments. In humans, each copy of this fifth protein-coding exon is 92 nucleotides in length, encoding 30 amino acids, of which one to three amino acids vary between the two exon copies for each gene (Fig. 1B). ' $A$ ' isoforms (5A) include the ancestral and canonical copy, with an aspartic acid residue (Asp/D) encoded at position 7 of $30 .{ }^{25}{ }^{\prime} \mathrm{N}$ ' isoforms (5N) use the alternative copy, with an asparagine (Asn/N) residue at position 7 of 30 in SCN1A, SCN2A, and $S C N 8 A$ and a serine residue (Ser/S) in SCN3A. Despite this relatively small change in protein structure, differential inclusion of $5 \mathrm{~N}$ or $5 \mathrm{~A}$ can have marked effects on channel function. Indeed, these splice isoforms can alter channel electrophysiological characteristics, ${ }^{26,27}$ the functional impacts of variants associated with seizure, ${ }^{23}$ neuronal excitability, ${ }^{28}$ response to anti-epileptics, ${ }^{21,22,26}$ and seizure-susceptibility. ${ }^{28}$

The utilization of the $5 \mathrm{~N}$ or $5 \mathrm{~A}$ varies across development, with $5 \mathrm{~N}$ generally being expressed at higher levels in the neonatal period while $5 \mathrm{~A}$ predominates in adults. ${ }^{27}$ This switch is defined best in mouse, where the $5 \mathrm{~N}: 5 \mathrm{~A}$ ratio varies by gene and brain region along with developmental stage. ${ }^{20}$ For $\operatorname{Scn} 2 a$ in mouse neocortex, the $5 \mathrm{~N}: 5 \mathrm{~A}$ ratio is $2: 1$ at birth (postnatal day 0/PO) and flips to $1: 3$ by P15. For both $S c n 3 a$ and Scn8a, 5A predominates throughout the postnatal period with a $1: 2$ ratio at PO increasing to $1: 5$ by P15. ${ }^{20} \mathrm{Scn} 1 \mathrm{a}$ lacks a functional copy of $5 \mathrm{~N}$ in the mouse genome. Similar developmental profiles currently have not been reported for humans beyond the of $5 \mathrm{~N} / 5 \mathrm{~A}$ utilization $S C N 1 \mathrm{~A}$ in adults, in which a $5 \mathrm{~N}: 5 \mathrm{~A}$ ratio of over 1:5 was observed in the temporal cortex and hippocampus of adult surgical resections. ${ }^{21,22}$ been reported for "exons $18 \mathrm{~N}$ or $18 \mathrm{~A}$ " in SCN8A only, regulated by the RNA-binding protein RBFOX1. ${ }^{16,29,30}$ Using GENCODE human v31 gene definitions, ${ }^{31} 18 \mathrm{~A}$ maps to the $20^{\text {th }}$ protein- 
105 coding exon of major SCN8A isoforms (CDS 20, Fig. 1A), while $18 \mathrm{~N}$ encodes the $8^{\text {th }}$ and last

106 protein-coding exon (CDS 8) of a shorter eight protein-coding exon transcript

107 (ENST00000548086.3, Fig. S1). In the embryonic mouse brain, most SCN8A transcripts include

$10818 \mathrm{~N}$ or skip both $18 \mathrm{~N}$ and $18 \mathrm{~A}$, leading to non-functional channels, while $18 \mathrm{~A}$ predominates in

109 the adult mouse and human brain. ${ }^{16}$

111 Here, we present data on the utilization of GENCODE-annotated protein-coding exons in four

112 seizure-associated voltage-gated sodium channels in the human and mouse neocortex across

113 development. We demonstrate a synchronized transition from 5N to 5A utilization between 24

114 post-conceptual weeks ( $2^{\text {nd }}$ trimester) and six years-of-age across all four voltage-gated sodium

115 channels and a transition from $18 \mathrm{~N}$ to $18 \mathrm{~A}$ in SCN8A from 13 post-conceptual weeks to 6

116 months-of-age. These isoform differences can modify the function of the encoded voltage-

117 gated sodium channels, raising the potential that interventions, such as antisense

118 oligonucleotides, could be used to modify the isoform ratio as a potential therapy for disorders

119 caused by variants in sodium channel genes or epilepsy. 


\section{Materials and Methods}

122

\subsection{Genomic data}

To quantify the relative proportion of protein-coding exon expression across development in the human cortex, we assessed bulk tissue RNA-seq data from 176 post mortem dorsolateral prefrontal cortex (DLPFC) samples from the BrainVar cohort. ${ }^{32}$ The BrainVar cohort also has corresponding whole-genome sequencing data that were used to derive per sample genotypes, as described previously. ${ }^{32}$ To assess corresponding patterns of exon expression in mouse cortex across development, we assessed 58 samples with bulk tissue RNA-seq data in wildtype C57/B6 mice. Thirty-four of these were generated as controls for ongoing experiments and 24 were downloaded from GEO. ${ }^{33}$

\subsection{Exon expression}

To assess exon expression in the human cortex, the 100bp paired-read RNA-seq data from BrainVar were aligned to the GRCh38.p12 human genome using STAR aligner ${ }^{34}$ and exon-level read counts for GENCODE v31 human gene definitions were calculated with DEXSeq ${ }^{35}$ and normalized to counts per million (CPM). ${ }^{36}$ Despite the similar amino acid sequence, the nucleotide sequence of $5 \mathrm{~N}$ and $5 \mathrm{~A}$ is sufficiently differentiated across the four genes that $100 \mathrm{bp}$ reads align unambiguously to one location in the genome. ${ }^{37}$ Reads were detected in $5 \mathrm{~N}$ and $5 \mathrm{~A}$ for all samples, across all four genes, with the exception of the SCN1A for which 31 of 176 samples (17.6\%) had no detectable $5 \mathrm{~N}$ reads (Fig. $2 \mathrm{~A}$ ). Along with quantifying the expression of $5 \mathrm{~N}$ and $5 \mathrm{~A}$ (Fig. 2), we also assessed expression for the surrounding constitutive exons, as a control (Fig. S2). For the mouse cortical data, the same analysis methods were used but with alternative references, specifically the $\mathrm{GRCm} 38 / \mathrm{mm} 10$ genome and GENCODE VM25 gene definitions. A similar approach was used to assess the utilization of $18 \mathrm{~N}$ and $18 \mathrm{~A}$ in SCN8A.

\subsection{Intron splicing}

We applied a complementary approach to detecting $5 \mathrm{~N}$ and $5 \mathrm{~A}$ exon usage by assessing intron splicing via reads that map across exon-exon junctions in the same 176 BrainVar samples. Reads were aligned with OLego aligner ${ }^{38}$ using the same genome build and gene definitions as for exon expression. Clusters of differential intron splicing were identified with Leafcutter ${ }^{39}$ and differences across development were detected by comparing 112 prenatal samples to 60 postnatal samples. No cluster was detected for 5N/5A in SCN1A, preventing assessment across development, but clusters were identified and assessed for the other three genes and for $18 \mathrm{~N} / 18 \mathrm{~A}$ in SCN8A (Figs. 3, 5).

\subsection{Quantitative trait locus (QTL) analysis}

Common variants with a minor allele frequency $\geq 5 \%$ in both the prenatal $(N=112)$ and postnatal $(N=60)$ samples and Hardy Weinberg equilibrium $p$ value $\geq 1 \times 10^{-12}$ were identified previously. ${ }^{32}$ Variants within one million basepairs of each sodium channel gene were extracted and integrated with the Leafcutter clusters, along with the first five principal components calculated from common variants identified in whole-genome sequencing data from these samples and 3,804 parents from the Simons Simplex Collection ${ }^{32,40}$ to predict sQTLs with FastQTL. ${ }^{41}$ This analysis was performed on all samples, prenatal-only samples, and postnatal- 
only samples, with false discovery rate (FDR) estimated from the results of each analysis using the Benjamini-Hochberg procedure. ${ }^{42}$ To assess correlation of $5 \mathrm{~N}$ expression for the SNP rs3812718, genotypes were extracted for chr2:166,053,034 C>T (GRCh38) and compared with $5 \mathrm{~N}$ expression calculated by DEXSeq, as described above.

\subsection{Statistical analysis}

171 The 5N:5A expression ratio was calculated from normalized exon expression values (CPM).

172 Linear regression was used to assess whether this ratio varied across development by

173 comparing the log-transformed 5N:5A ratio to log-transformed post-conceptual days (Fig. 2).

174 The difference in ratio was also assessed between the mid-late fetal samples $(\mathrm{N}=112)$ and

175 childhood/adolescent/young adult samples $(\mathrm{N}=35)$ with a two-tailed Wilcoxon test. To compare

176 intron splicing between prenatal and postnatal samples, we used the P-values estimated with a

177 Dirichlet-multinomial generalized linear model, as implemented in Leafcutter. ${ }^{39}$

\section{Results}

\subsection{Expression of voltage-gated sodium channels in the human cortex}

182 Gene expression varies dramatically across development for many genes, especially during the 183 late-fetal transition, during which half the genes expressed in the brains undergo a concerted 184 increase or decrease in expression. ${ }^{12,32,43,44}$ To assess gene-level developmental trajectories, we 185 analyzed bulk-tissue RNA-seq of the human DLPFC in 176 post mortem samples from the BrainVar cohort (104 male, 72 female, spanning 6 post-conceptual weeks to 20 years after birth). ${ }^{32}$ The gene-level expression profile of all four voltage-gated sodium channels changes during this late-fetal transition (Fig. 1F-I), with SCN1A, SCN2A, and SCN8A expression rising from mid-fetal development through infancy to early childhood, while SCN3A expression falls. 

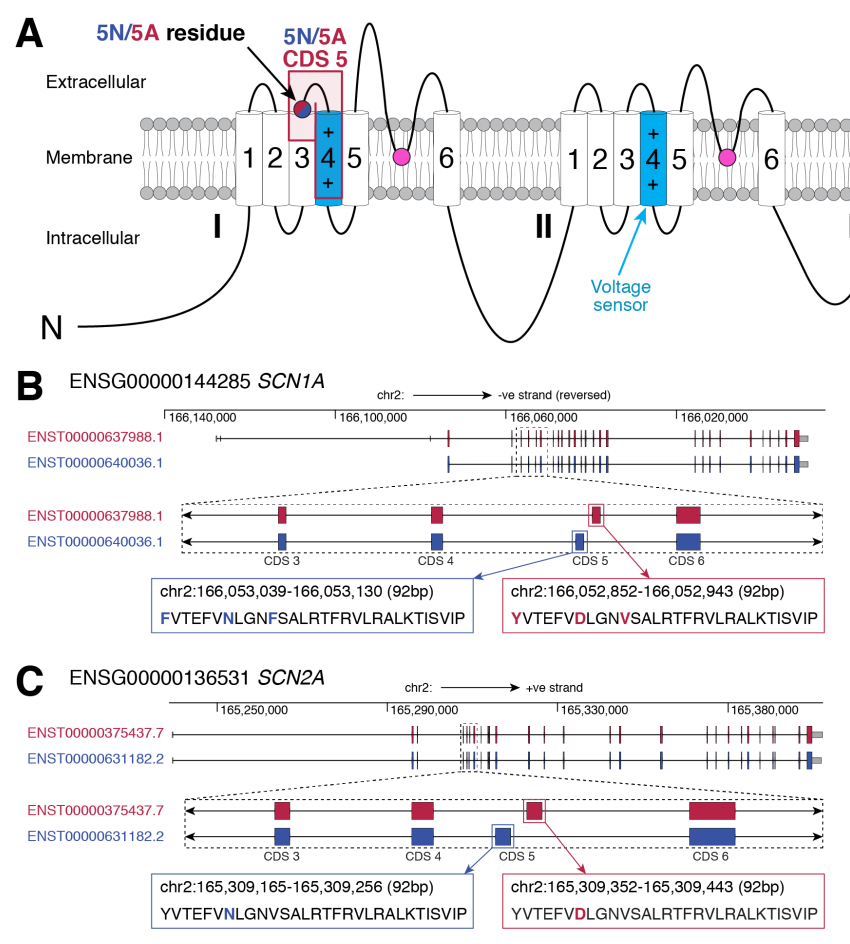

F ENSG00000144285 SCN1A
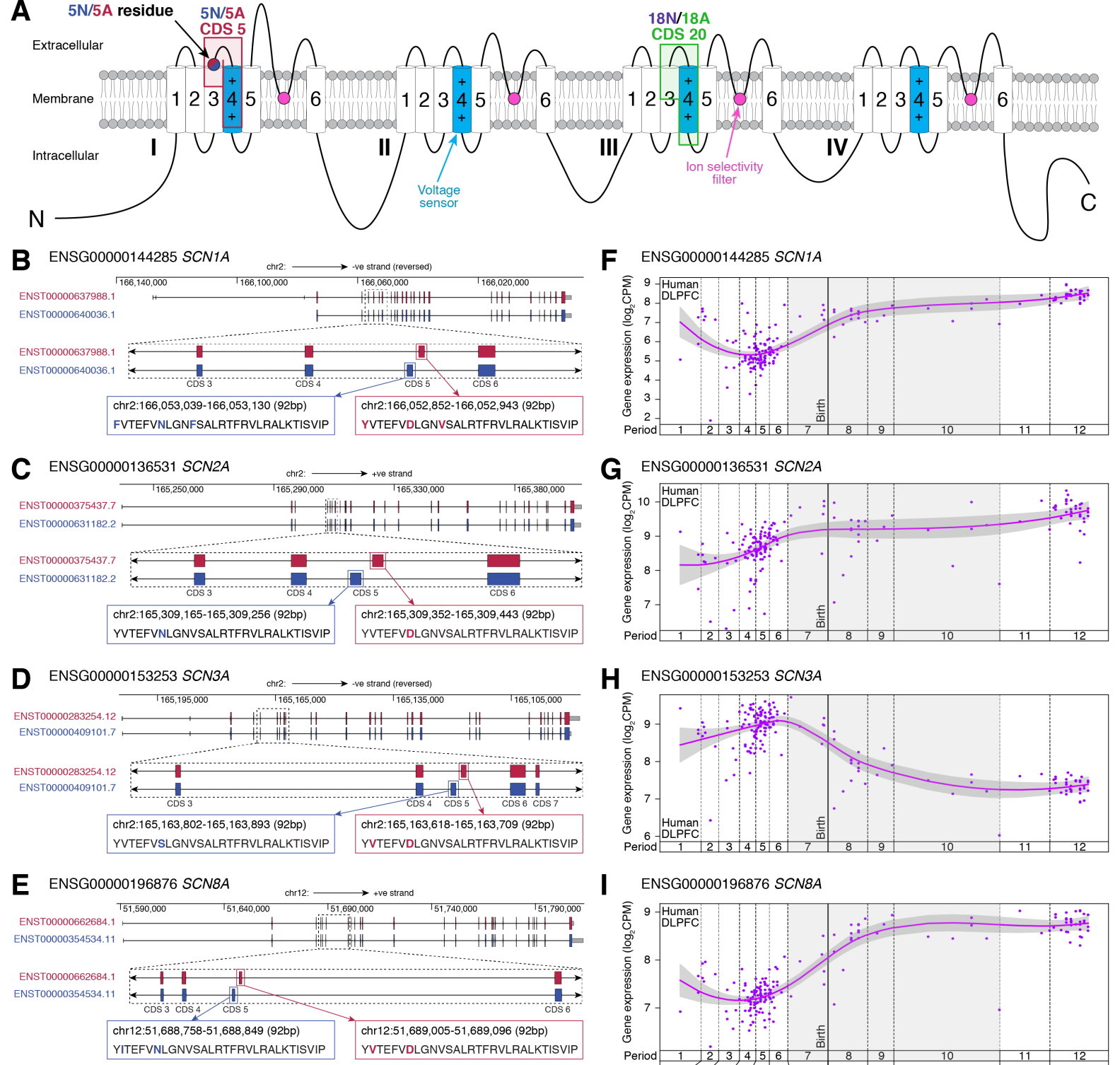

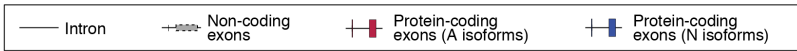

I ENSG00000196876 SCN8A

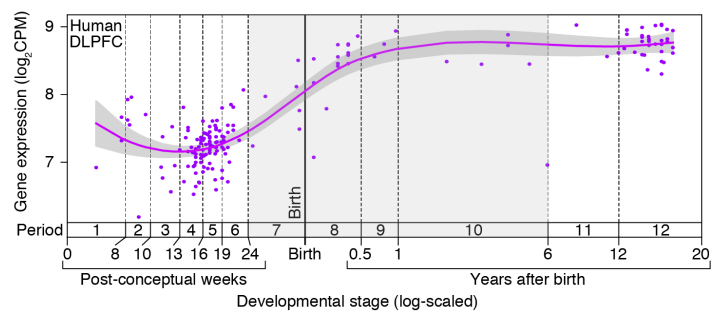

Figure 1. Splicing isoforms in voltage-gated sodium channels. A) Voltage-gated sodium channels are composed of four similar domains (I, II, III, IV), each of which includes six transmembrane segments with extracellular or intracellular linkers. The fourth transmembrane segment (S4) in each domain acts as a voltage sensor. Between the fifth and sixth transmembrane segment $(\mathrm{S} 5, \mathrm{~S} 6)$ is a pore loop that forms the ion selectivity filter. The fifth protein-coding exon ( $5 \mathrm{~N} / 5 \mathrm{~A}, \mathrm{CDS} 5)$ encodes a portion of the first domain, while the $20^{\text {th }}$ protein-coding exon (18N/18A, CDS 20) encodes a similar portion of the third domain. B) Location, genomic coordinates (GRCh38/hg38), and amino acid sequence of the ' $5 A^{\prime}$ ' and ' $5 \mathrm{~N}$ ' exons four sodium channels. C) Patterns of whole-gene expression in the human dorsolateral prefrontal cortex (DLPFC) across prenatal and postnatal development from the BrainVar dataset ${ }^{32}$. CPM: counts per million. Genomic coordinates are based on GRCh38/hg38 using GENCODE v31 gene definitions.

\subsection{Developmental trajectories of $5 \mathrm{~N}$ and $5 \mathrm{~A}$ expression in the human cortex} across development (Fig. S3), however all four sodium channels show dynamic changes in the 
207 expressed at a higher level than 5A in the mid-fetal brain but this reverses soon after birth.

208 Plotting the 5N:5A ratio allows exon utilization to be assessed independent of changes in gene

209 expression (Fig. 2). All four genes show changes in the $\mathrm{N}$ :A ratio across development, with a

210 modest change for SCN1A ( 0.14 fetal to 0.02 childhood/adolescent; $p=0.00003$, two-sided

211 Wilcoxon test, Figure 2B) and dramatic changes for $\operatorname{SCN} 2 A\left(3.7\right.$ to $0.09 ; p=5 \times 10^{-19}$, Fig. 2D),

$212 \operatorname{SCN} 3 A$ (0.96 to $0.18 ; p=6 \times 10^{-18}, \mathrm{Fig}$. $2 \mathrm{~F}$ ), and SCN8A (3.7 to $0.09 ; \mathrm{p}=5 \times 10^{-19}$, Fig. $2 \mathrm{H}$ ). As a

213 control, we applied this approach to assess the ratio of CDS 4 and CDS 6 across development.

214 We observed no developmental shift in the 4:6 ratio for SCN1A, SCN2A, and SCN3A, however

215 the exon 4:6 ratio is marginally higher than expected in the prenatal period for SCN8A (0.82 vs.

$2160.66 ; 9 \times 10^{-10}$, Fig. S2). This developmental variation in SCN8A is not observed for the

217 surrounding protein-coding exons and reflects a modest increase in CDS 4 expression in the

218 prenatal period, based on the expected expression given the exon length (Fig. S4). 
bioRxiv preprint doi: https://doi.org/10.1101/2020.11.18.389171; this version posted November 19, 2020. The copyright holder for this preprint (which was not certified by peer review) is the author/funder, who has granted bioRxiv a license to display the preprint in perpetuity. It is made available under aCC-BY-NC 4.0 International license.

A ENSG00000144285 SCN1A, 5N/5A

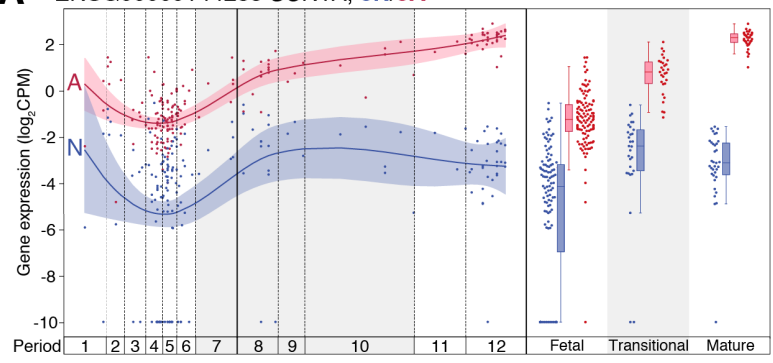

C ENSG00000136531 SCN2A, 5N/5A

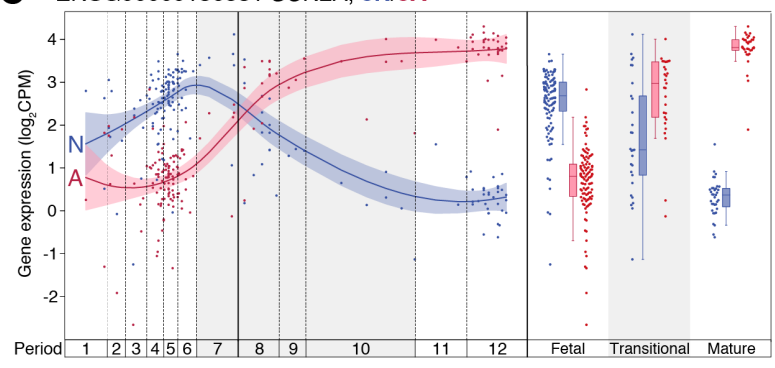

E ENSG00000153253 SCN3A, 5N/5A

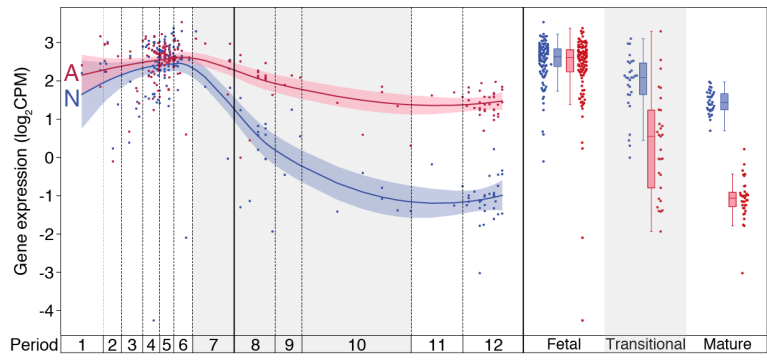

G ENSG00000196876 SCN8A, 5N/5A

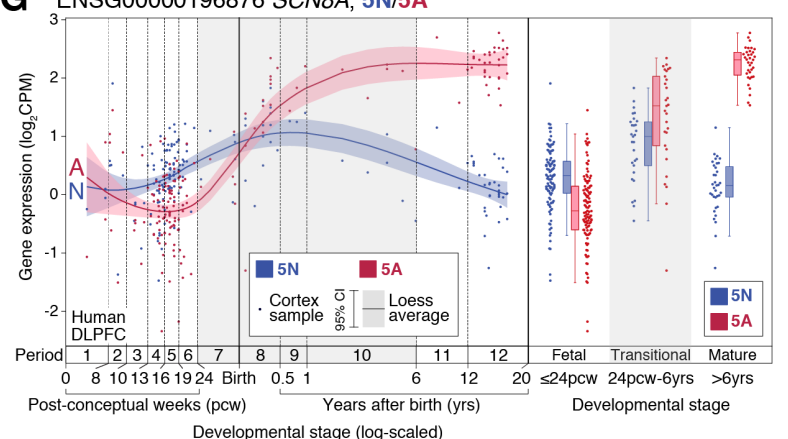

B ENSG00000144285 SCN1A, 5N/5A

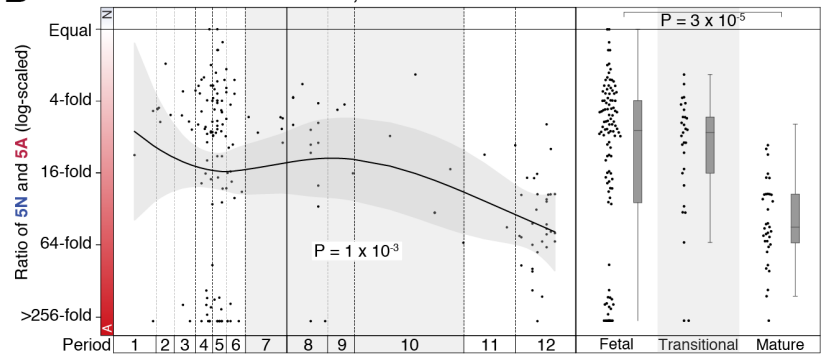

D ENSG00000136531 SCN2A, 5N/5A

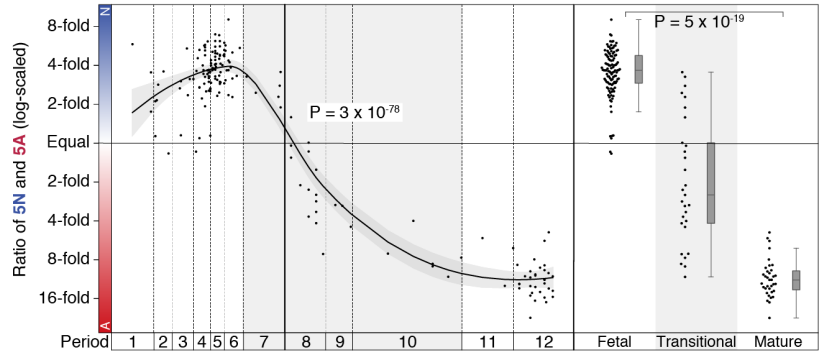

F ENSG00000153253 SCN3A, 5N/5A

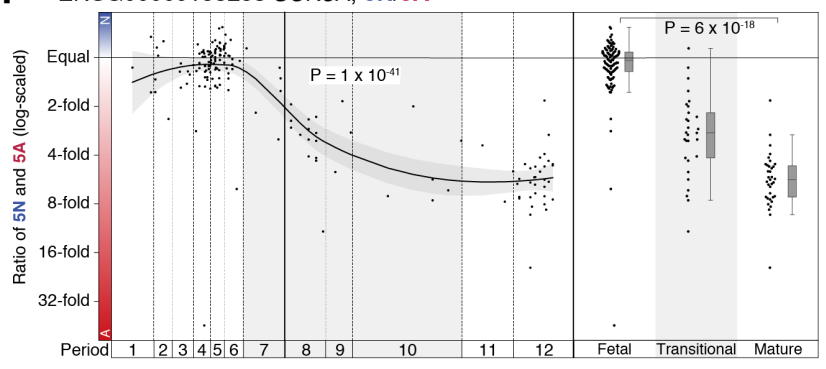

H ENSG00000196876 SCN8A, 5N/5A

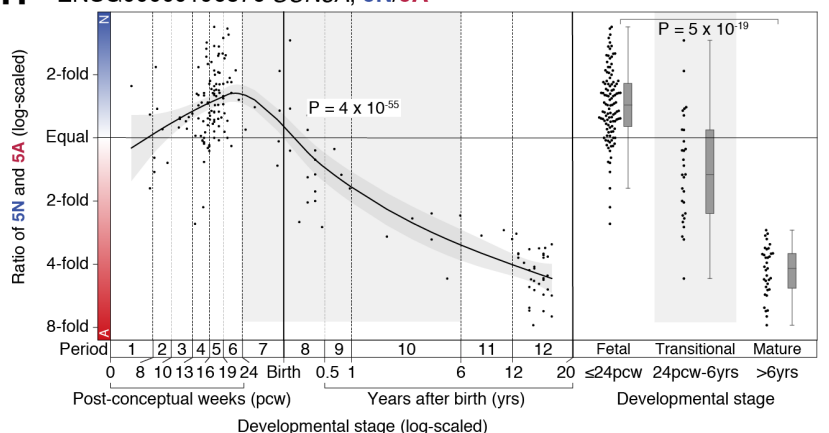

Figure 2. Expression of $\mathbf{5 N}$ and $\mathbf{5 A}$ in the human cortex across development. $A$ ) The expression of $5 \mathrm{~N}$ (blue) and $5 \mathrm{~A}$ (red) in SCN1A is shown for 176 BrainVar human cortex (DLPFC) samples across development (points). On the left, the colored line shows the Loess smoothed average and 95\% confidence interval (shaded region). On the right, boxplots show the median and interquartile range for the same data, binned into fetal, transitional, and mature developmental stages. B) The ratio of $5 \mathrm{~N}$ and $5 A$ expression from panel ' $A$ ' is shown across development (left) and in three developmental stages (right). C-H) Panels A and B are repeated for the genes SCN2A, SCN3A, SCN8A. For comparison, the same plots for CDS four and six are shown in Figure S2. CPM: Counts per million; DLPFC: Dorsolateral prefrontal cortex. Statistical tests: B, D, F, H) Left panel, linear regression of $\log _{2}\left(5 \mathrm{~N}: 5 \mathrm{~A}\right.$ ratio) and $\log _{2}$ (post-conceptual days). Right panel, two-tailed Wilcoxon test of $\log _{2}(5 \mathrm{~N}: 5 \mathrm{~A}$ ratio) values between fetal and mature groups.

\subsection{Intron splicing around $5 \mathrm{~N}$ and $5 \mathrm{~A}$ in the human cortex}


To verify that mutually exclusive use of $5 \mathrm{~N}$ and $5 \mathrm{~A}$ underlies the observed exon expression changes (Fig. 2), we considered RNA-seq reads that spanned exon-exon junctions to quantify intron splicing. Clusters of differential intron splicing corresponding to $5 \mathrm{~N} / 5 \mathrm{~A}$ usage were identified by Leafcutter for SCN2A, SCN3A, and SCN8A (Fig. 3), but not SCN1A, likely due to the consistently low expression of $\mathrm{N}$ isoforms (Fig. 2). The splicing patterns for $S C N 2 A, S C N 3 A$, and SCN8A are consistent with the observed exon expression changes (Fig. 2, 3) and at least $99 \%$ of reads are consistent with mutually exclusive $5 \mathrm{~N} / \mathrm{A}$ utilization.

\section{A ENSG00000136531 SCN2A}

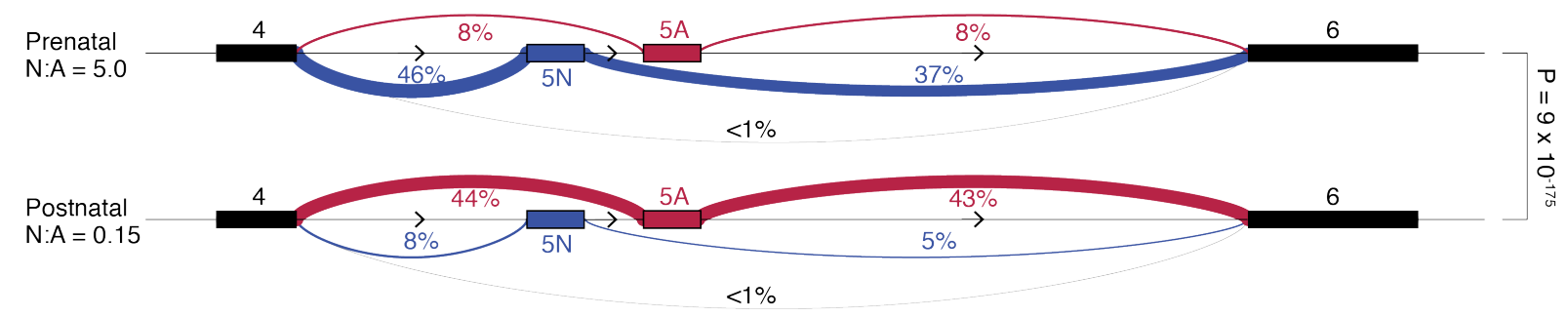

\section{B ENSG00000153253 SCN3A (reversed)}

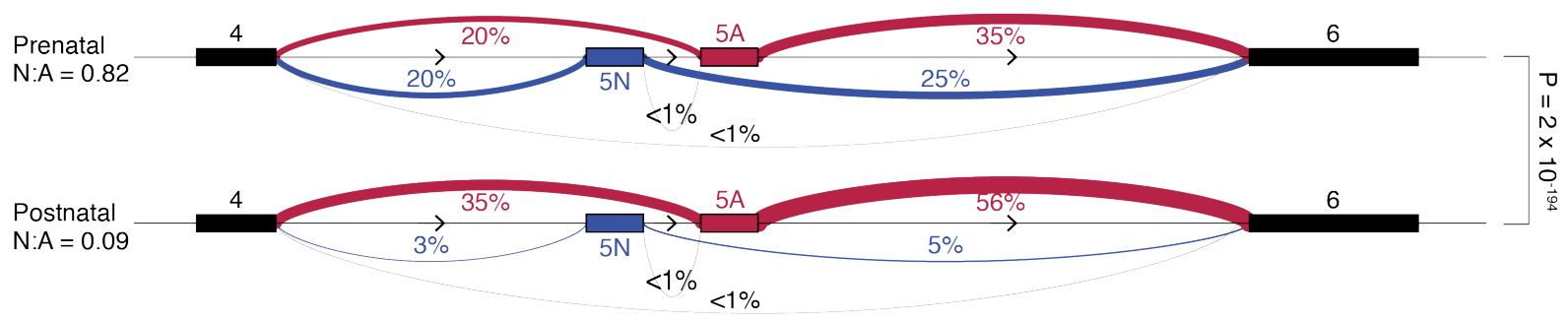

\section{C ensG00000196876 SCN8A}

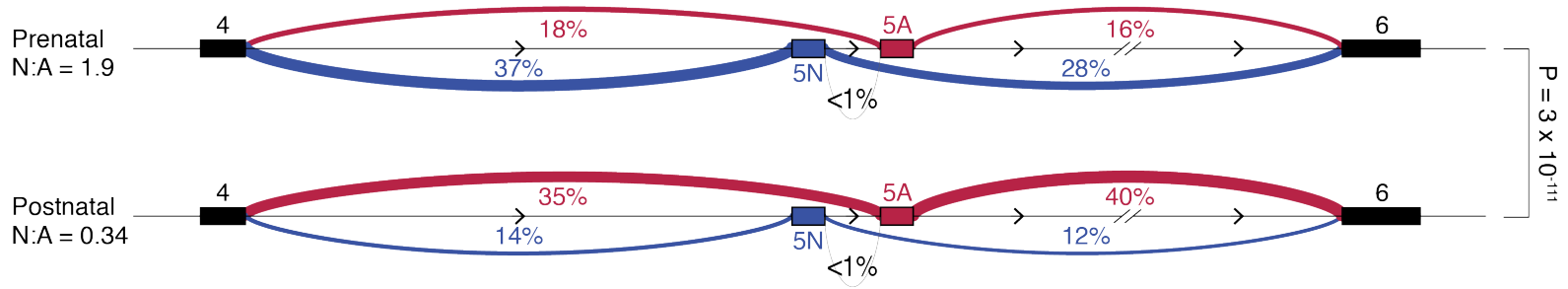

Figure 3. Intron splicing of sodium channel genes in the developing human cortex. A) Sashimi plot of splicing in the prenatal (top, $\mathrm{N}=112$ samples) and postnatal (bottom, $\mathrm{N}=60$ samples) DLPFC for SCN2A. Linewidth is proportional to percentage of split reads observed for each intron and this value is given as a percentage. Introns related to $5 \mathrm{~N}$ inclusion are shown in blue, those related to $5 \mathrm{~A}$ inclusion are shown in red, and others are in grey. B-C) Equivalent plots for SCN3A (a negative strand gene with the orientation reversed to facilitate comparison to the other two genes) and SCN8A. P-values compare the prenatal and postnatal cluster using a Dirichlet-multinomial generalized linear model, as implemented in Leafcutter. ${ }^{39}$

\subsection{Developmental trajectories of $5 \mathrm{~N}$ and $5 \mathrm{~A}$ expression in the mouse cortex}

251 We repeated the analysis of sodium channel 5N/5A expression using bulk tissue RNA-seq data 252 from the mouse cortex across development ( $N=58$; E15.5 to P75). Our data are consistent with 253 the N:A ratios described previously. ${ }^{20}$ We observe more substantial differences at the extremes of development: SCN2A (3.3 fetal to 0.06 mature; $p=0.00003$, two-sided Wilcoxon test, Fig. 4C), 
bioRxiv preprint doi: https://doi.org/10.1101/2020.11.18.389171; this version posted November 19, 2020. The copyright holder for this preprint (which was not certified by peer review) is the author/funder, who has granted bioRxiv a license to display the preprint in perpetuity. It is made available under aCC-BY-NC 4.0 International license.

SCN3A (2.4 to $0.14 ; p=0.00008$, Fig. $4 \mathrm{E})$, and SCN8A (1.8 to $0.22 ; \mathrm{p}=0.00003$, Fig. $4 \mathrm{G}$ ). Mice lack a functional $5 \mathrm{~N}$ exon in SCN1A.

A ENSMUSG00000064329, Scn1a, 5N/5A

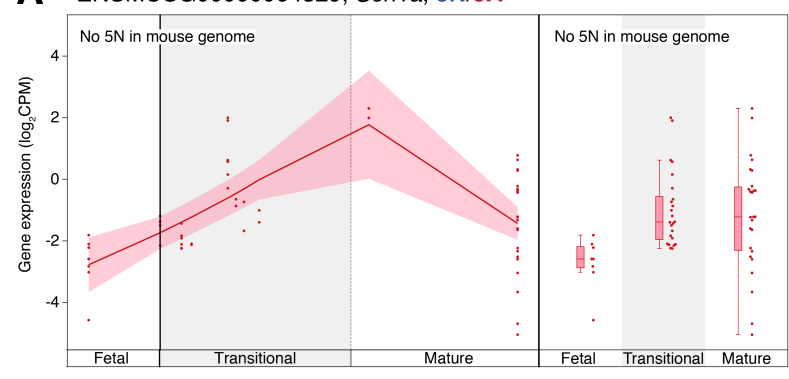

C ensmusG00000075318, Scn2a, 5N/5A

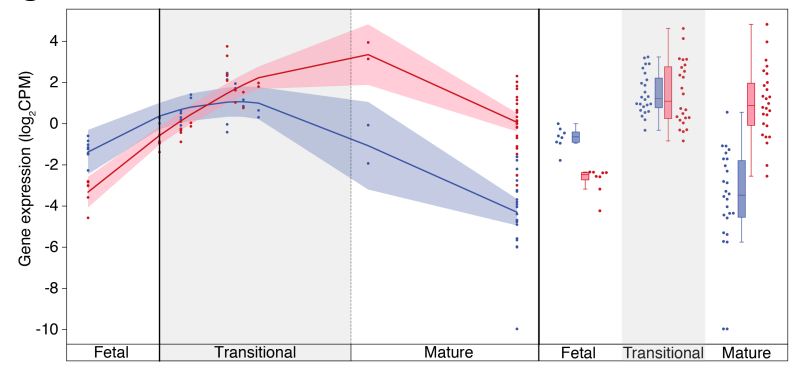

E ENSMUSG00000057182, Scn3a, 5N/5A

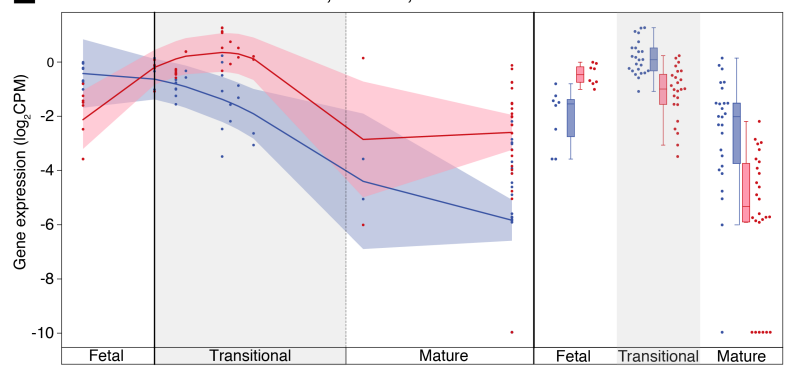

G ENSMUSG00000023033, Scn8a, 5N/5A

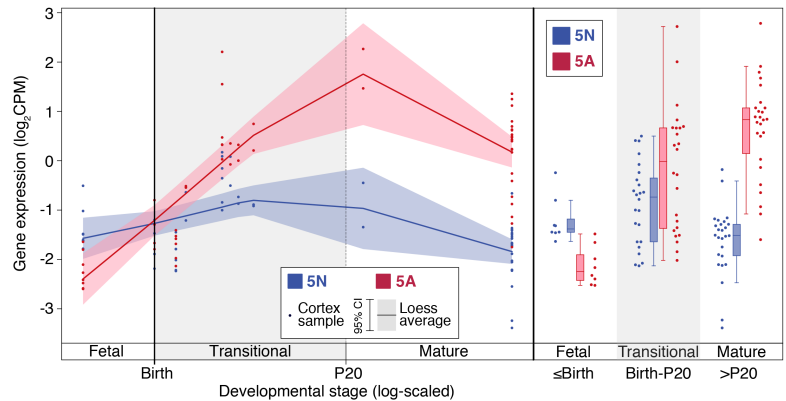

B
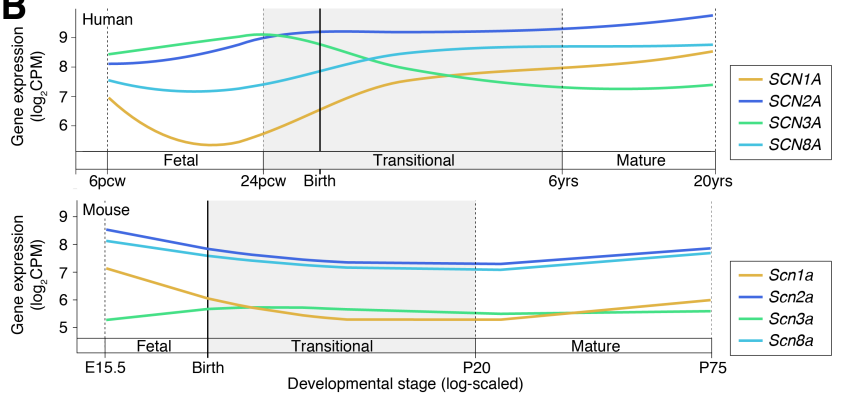

D ENSMUSG00000075318, Scn2a, 5N/5A

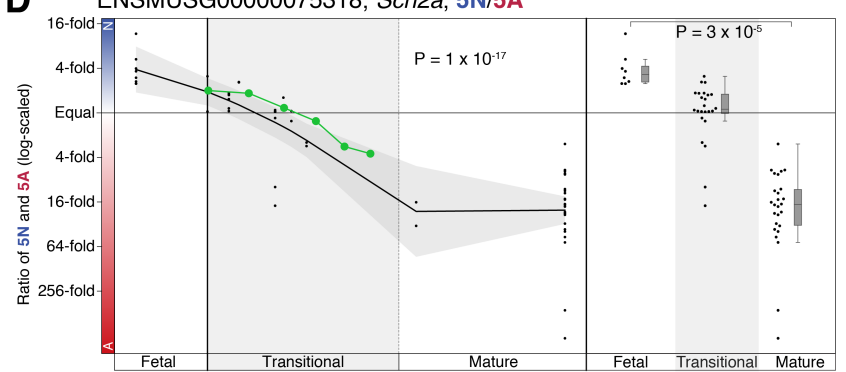

F enSmusG00000057182, Scn3a, 5N/5A

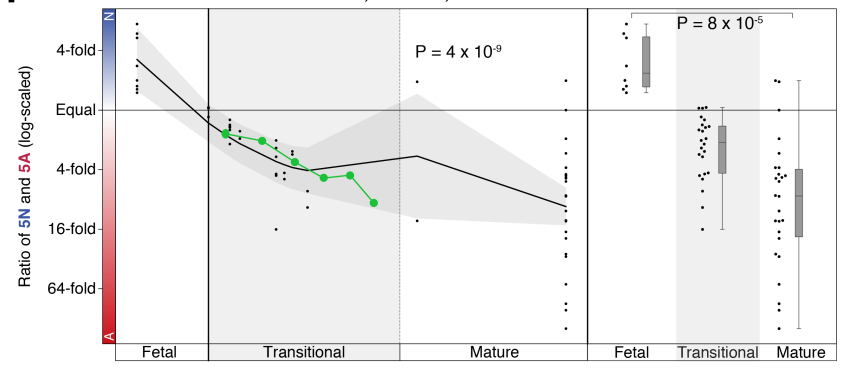

H ENSMUSG00000023033, Scn8a, 5N/5A

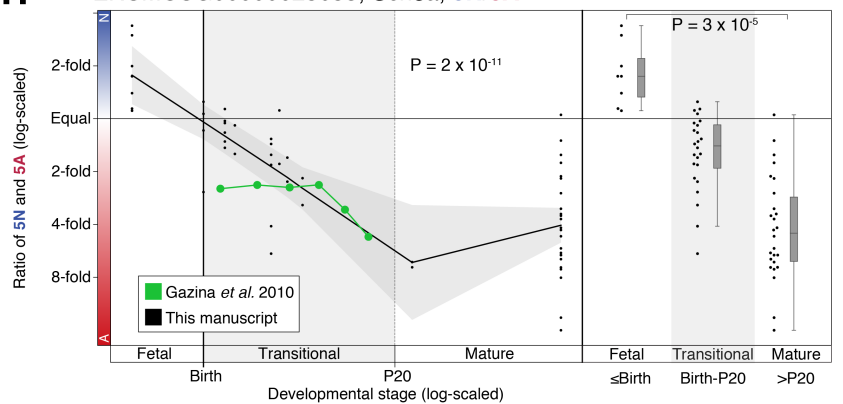

Figure 4. Expression of $5 \mathrm{~N}$ and $\mathbf{5 A}$ in the mouse cortex across development. A) The expression of 5A (red) in Scn 1a is shown for 58 mouse cortex samples across development (points); no functional $5 \mathrm{~N}$ equivalent is present in the mouse genome. On the left, the colored line shows the Loess smoothed average and $95 \%$ confidence interval (shaded region). On the right, boxplots show the median and interquartile range for the same data, binned into fetal, transitional, and mature developmental stages. B) The Loess smoothed average expression of the four voltage-gated sodium channels in human cortex (top, Fig. 1) and mouse cortex (bottom). C) Panel ' $A$ ' is repeated for Scn2a with the inclusion of $5 \mathrm{~N}$ (blue). D) The ratio of $5 \mathrm{~N}$ and $5 \mathrm{~A}$ expression from panel ' $C$ ' is shown across development (left) and in three developmental stages (right). Values reported previously in mouse cortex are shown in the same scale in green for comparison ${ }^{20}$. E-H) Panels ' $C$ ' and ' $D$ ' are repeated for the genes Scn3a, Scn8a. 
CPM: Counts per million. Statistical tests: D, F, H) Left panel, linear regression of $\log _{2}\left(5 \mathrm{~N}: 5 \mathrm{~A}\right.$ ratio) and $\log _{2}$ (post-conceptual days). Right panel, two-tailed Wilcoxon test of $\log _{2}(5 \mathrm{~N}: 5 \mathrm{~A}$ ratio) values between fetal and mature groups.

\subsection{No evidence of common polymorphisms regulating $5 \mathrm{~N}$ or $5 \mathrm{~A}$ utilization} A common polymorphism ( $r$ 3812718, GRCh38 chr2:166,053,034 C>T, IVS5N+5G>A) has previously been associated with epilepsy, seizures, and response to anti-epileptics, ${ }^{21,22,26,45,46}$ though this variant did not reach genome-wide significance in a mega-analysis of epilepsy. ${ }^{47}$ Prior analyses of expression in the adult human temporal cortex showed evidence that the homozygous variant allele (TT in DNA, AA in CDNA) was associated with reduced utilization of $5 \mathrm{~N} .^{21,48}$ We do not observe evidence for such a relationship in the prenatal or postnatal prefrontal cortex (Fig. S5) and this polymorphism is not identified as a splicing quantitative trait locus (QTL) in GTEx. ${ }^{49}$ Furthermore, this variant is not predicted to alter splicing behavior using the SpliceAl algorithm. ${ }^{50}$ The TT genotype is associated with increased expression of SCN1A in the adult human basal ganglia with $\left(p=1 \times 10^{-10}\right) \cdot{ }^{49}$

\subsection{Developmental trajectories of $18 \mathrm{~N}$ and $18 \mathrm{~A}$ expression in SCN8A} We next considered the developmental timing of the transition between $18 \mathrm{~N}$ and $18 \mathrm{~A}$ in SCN8A

(Fig. 1A, 5A). Intron splicing shows a robust difference between prenatal and postnatal human dorsolateral prefrontal cortex $\left(P=4 \times 10^{-185}\right.$, Fig. $5 B$ ), with the prenatal period characterized by high frequencies of transcripts excluding $18 \mathrm{~A}$, either including $18 \mathrm{~N}$ or skipping both $18 \mathrm{~N}$ and $18 \mathrm{~A}$, while in the postnatal cortex $18 \mathrm{~A}$ is included in $93 \%$ of reads. Considering exon expression post-conceptual weeks and continues till six months-of-age, with both timepoints being earlier than the equivalents for $5 \mathrm{~N} / 5 \mathrm{~A}$ in $S C N 8 \mathrm{~A}$ and the other genes.

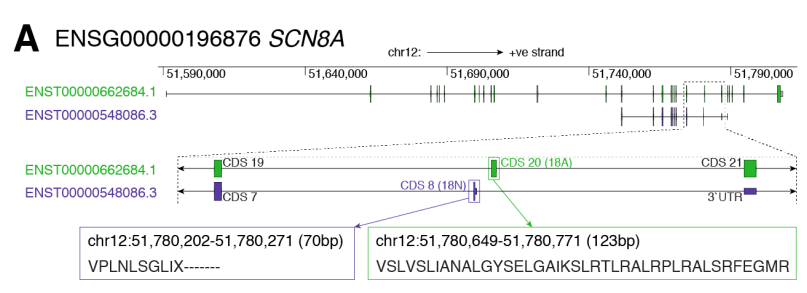

B ENSG00000196876 SCN8A

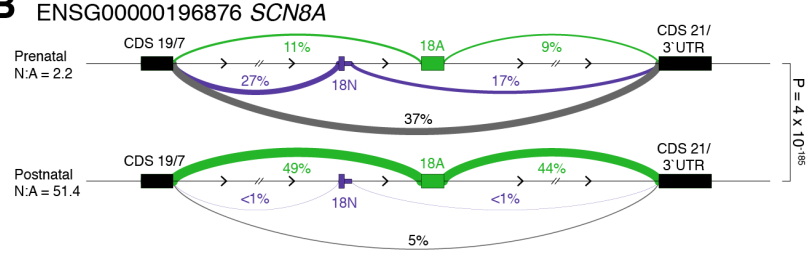

C ENSG00000196876 SCN8A, 18N/18A
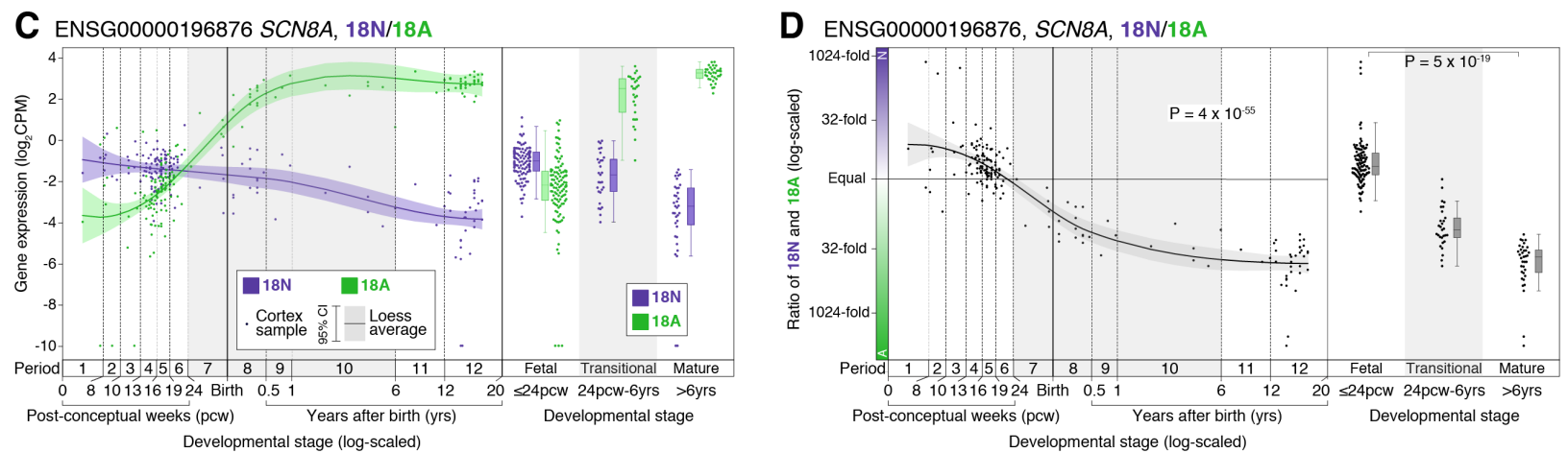

Figure 5. Developmental trajectories of CDS 20 (18N/18A) in human cortex in SCN8A. A) Location, genomic coordinates (GRCh38/hg38), and amino acid sequence of the 18N and 18A exons in SCN8A. B) Sashimi plot of intron splicing in the prenatal (top, $\mathrm{N}=112$ samples) and postnatal (bottom, $\mathrm{N}=60$ samples) dorsolateral prefrontal cortex. Linewidth is proportional to percentage of reads observed for each exon-exon junction and this value is also shown as a percentage. Introns related to $18 \mathrm{~N}$ exon inclusion are shown in purple, those related to 18A exon inclusion are shown in green, and others are in grey. C) 
Expression of the $18 \mathrm{~N}$ (purple) and 18A (green) for 176 BrainVar human dorsolateral prefrontal cortex samples across development (points). On the left, the colored line shows the Loess smoothed average with the shaded area showing the $95 \%$ confidence interval. On the right, boxplots show the median and interquartile range for the same data, binned into fetal, transitional, and mature developmental stages. D) The $18 \mathrm{~N}$ : $18 \mathrm{~A}$ ratio is shown for each sample from panel ' $C$ ' across development (left) and binned into three groups (right). CPM: Counts per million; Statistical analyses: B) Dirichlet-multinomial generalized linear model, as implemented in Leafcutter, $\left.{ }^{39} \mathrm{D}\right)$ Left panel, linear regression of $\log _{2}\left(18 \mathrm{~N}: 18 \mathrm{~A}\right.$ ratio) and $\log _{2}$ (postconceptual days). Right panel, two-tailed Wilcoxon test of $\log _{2}(18 \mathrm{~N}: 18 \mathrm{~A}$ ratio) values between fetal and mature groups.

\subsection{Other annotated protein-coding exons with distinct developmental trajectories} To assess whether other protein-coding exons undergo distinct developmental transitions (Fig. S3), we calculated the ratios of all pairs of protein-coding exons within each for the four sodium channel genes and assessed whether the ratio was correlated with development stage using linear regression. This is the same calculation used to quantify the $5 \mathrm{~N} / 5 \mathrm{~A}$ and $18 \mathrm{~N} / 18 \mathrm{~A}$ transitions (Fig. 2, 5D) and distinguishes exons with expression profiles that differ from the rest of the gene (e.g. 5A in SCN2A), rather than simply being expressed at reduced levels, suggesting alternative regulatory processes (Fig. S3). Visualizing the $R^{2}$ values of these correlations provides simple method to identify the such distinct trajectories (Fig. 6). Aside from 5N/5A and, in SCN8A, 18N/18A, no protein-coding exons common to most isoforms (consistent CDS in Fig. S3) show differential expression, but a few weakly expressed protein-coding exons specific to a small number of isoforms (variable CDS in Fig. S3) do vary across development (Fig. 6).

GENCODE defines seven variable CDS exons for SCN1A (DEXSeq divisions: 006, 015, 021, 031, 034, 047, 049; Table S2, Fig. 6A). Of these, only 021 shows a distinct developmental trajectory (Fig. 6A), with reduced postnatal expression relative to other SCN1A exons (Fig. S3). This result is verified by the intron splicing data ( $p=6 \times 10^{-91}$, Leafcutter). 
bioRxiv preprint doi: https://doi.org/10.1101/2020.11.18.389171; this version posted November 19, 2020. The copyright holder for this preprint (which was not certified by peer review) is the author/funder, who has granted bioRxiv a license to display the preprint in perpetuity. It is made available under aCC-BY-NC 4.0 International license.

\section{A ENSG00000144285, SCN1A}

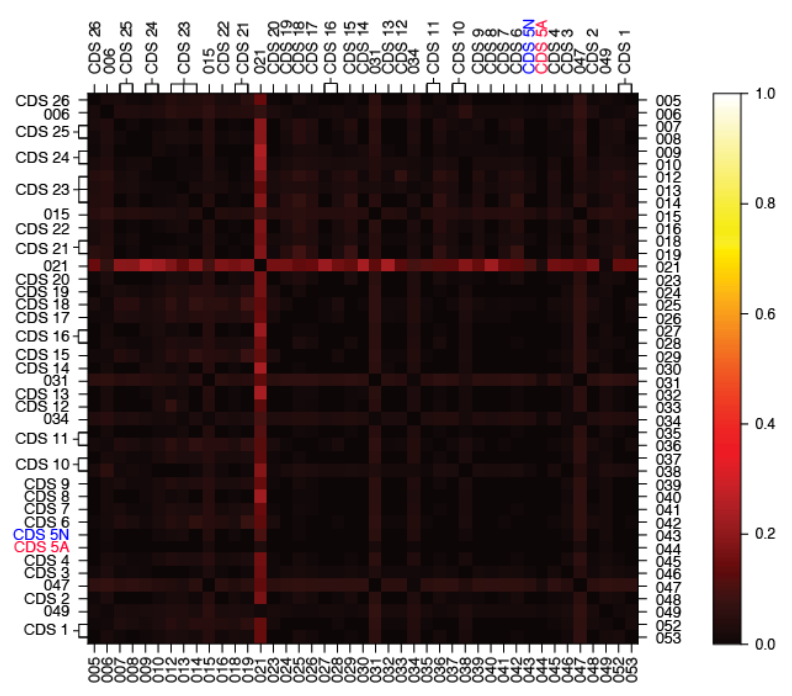

C ENSG00000153253, SCN3A

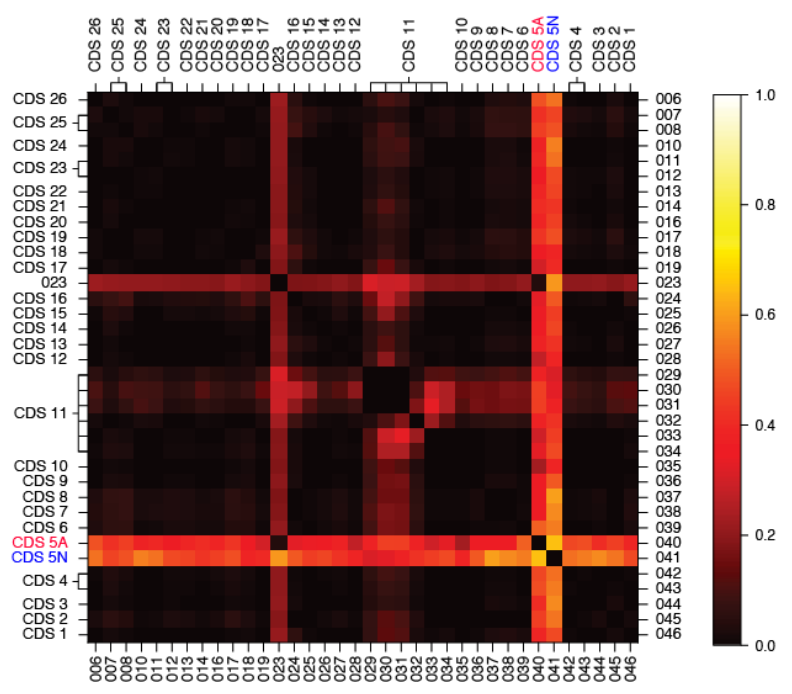

\section{B ENSG00000136531, SCN2A}

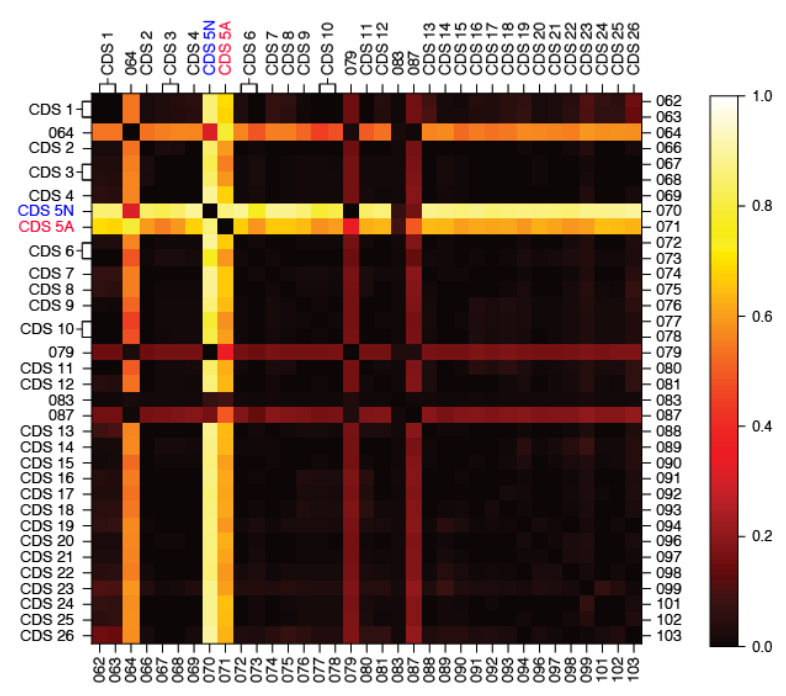

D

D ENSG00000196876, SCN8A

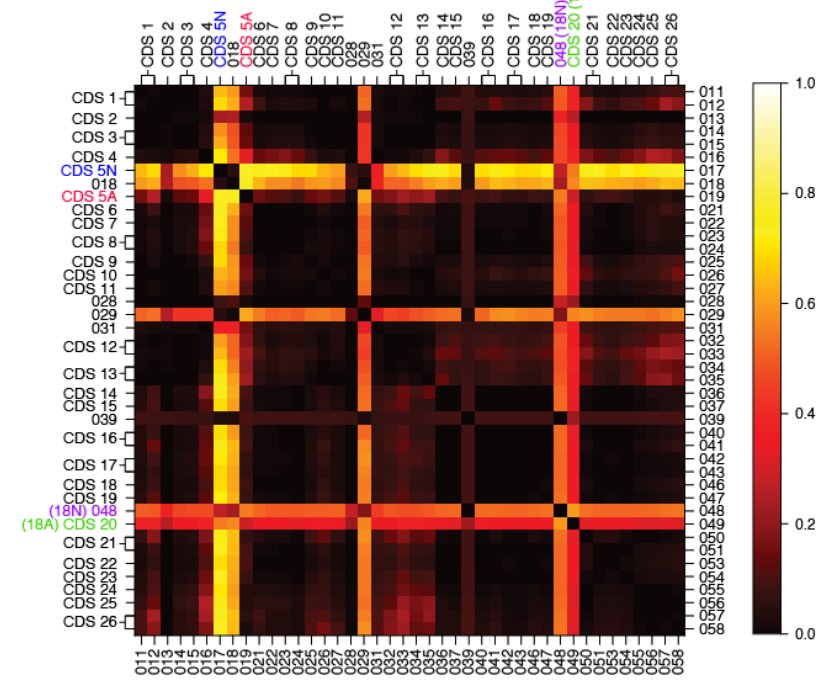

Figure 6. Identification of protein-coding exons with complex developmental trajectories. A) The correlation between the ratio of CPM expression between pairs of exons (log-scaled) and developmental stage (post conceptual days, log-scaled) for SCN1A was assessed with a linear model (e.g. Fig. 2B). The $\mathrm{R}^{2}$ value of each exon pair is show as a heat map with 'hot' colors representing exon-pairs with high $R^{2}$ values for which variation in the ratio is correlated with developmental age, i.e. pairs of exons that show substantially different expression across development. Exon numbers from DEXSeq (Table $\mathrm{S} 2$ ) are shown on the bottom and right and equivalent CDS number on the top and left (see Table S2). B-D) The analysis is repeated for SCN2A, SCN3A, and SCN8A.

In SCN2A, the 5N/5A trajectories stand out clearly (Fig. 6B). There are four variable CDS exons (DEXSeq divisions: 064, 079, 083, 087; Table S2, Fig. 6B), three of which have distinct developmental trajectories (Fig. 6B, S3): 064 (Fig. S3, P = 2 $\times 10^{-12}$, Leafcutter), 079 (Fig. S3, P = 7 $\times 10^{-33}$, Leafcutter), 087 (Fig. S3, $\mathrm{P}=2 \times 10^{-20}$, Leafcutter). The single variable CDS exon in $S C N 3 A, 023$ (Table S2, Fig. 6C), varies across development (Fig. S3, $\mathrm{P}=3 \times 10^{-80}$, Leafcutter). Finally, aside from $18 \mathrm{~N}$, there are five variable CDS exons in SCN8A (DEXSeq divisions: 018, 028, 
029, 031, 039; Table S2, Fig. 6D) of which 018 and 029 vary across development (Fig. 6D), but neither of these are validated by Leafcutter.

\section{Discussion} Using transcriptomic data from 176 human dorsolateral prefrontal cortex samples, we characterized the developmental patterns for all protein-coding exons in SCN1A, SCN2A, SCN3A, and SCN8A (Fig. 6, S3). We observed a coordinated decrease in the 5N:5A ratio between 24 post-conceptual weeks ( $2^{\text {nd }}$ trimester) and six years-of-age that is synchronized with widespread transcriptomic changes in the brain during the late-fetal transition. ${ }^{32,44}$ This is preceded by a similar decrease in the $18 \mathrm{~N}$ : $18 \mathrm{~A}$ ratio in SCN8A from 13 post-conceptual weeks to 6 months-of-age, which is regulated by RBFOX1. By analyzing a wider developmental window than prior analyses ${ }^{20,21,48}$ we observed more dynamic changes and larger disparities in exon expression.

Recent advances have shown that differential splicing patterns can be effective therapeutic targets in humans, for example through intrathecal antisense oligonucleotides. ${ }^{51,52}$ Since the electrophysiological consequences of some epileptic encephalopathy associated variants differ between $5 \mathrm{~N}$ and $5 \mathrm{~A}$, manipulating this ratio may offer therapeutic benefit in individuals carrying these variants. We consider three therapeutic scenarios.

First, for individuals with disorder-associated genetic variants within the 30 amino acids encoded by the $5^{\text {th }}$ exon, expressing the other copy of the $5^{\text {th }}$ exon could skip the variant. Theoretically, this approach could benefit individuals with both loss-of-function (proteintruncating variants, missense, splice site) and gain-of-function (missense) variants in the $5^{\text {th }}$ exon. At present, ten such cases have been identified, all with epileptic encephalopathy variants identified in the $5 \mathrm{~A}$ exon of SCN2A and SCN8A. ${ }^{53,54}$ Since the total transcript level would be unchanged, this strategy may provide a wider therapeutic window than simply decreasing expression levels. The success of the therapy would depend upon the proportion of transcripts expressing the alternate $5^{\text {th }}$ exon and the ability of this exon to functionally replace the original $5^{\text {th }}$ exon.

Second, splice isoforms can also have an effect on the biophysical effects of variants outside the $5^{\text {th }}$ exon. For example, three recently characterized epileptic encephalopathy associated variants in SCN2A-T236S, E999K, and S1336Y - all exhibit more pronounced alterations in their electrophysiological properties in $5 \mathrm{~N}$ Nav1.2 isoforms. ${ }^{23}$ Two other epileptic encephalopathyassociated variants - M252V and L1563V-exhibit biophysical changes only when expressed on $5 \mathrm{~N}$ isoform. ${ }^{14,55}$ For individuals with these mutations, tilting expression towards the $5 \mathrm{~A}$ isoform could provide some symptomatic improvement, especially during infancy. Including both the $5 \mathrm{~N}$ and $5 \mathrm{~A}$ isoforms in functional characterization of variant impact may identify many more such variants. ${ }^{23}$ 
glutamatergic neurons. ${ }^{11}$ Reverting expression to the fetal/neonatal state by encouraging $5 \mathrm{~N}$ utilization could reduce the excitability of cortical glutamatergic neurons, potentially limiting seizures. Since this would require repeated intrathecal administration, it would likely be limited to the most severe cases of epilepsy. Furthermore, it remains to be seen whether this approach could offer therapeutic benefits above and beyond existing antiepileptic drugs.

Our analysis was limited by the use of short-read transcriptomic data, leading us to focus on quantifying exon-level expression (Fig. 2) and splice junction usage (Fig. 3), rather than relying on estimates of isoform utilization (Fig. S1). We also elected to focus on protein-coding transcripts and exons defined by GENCODE (v31) rather than attempting de novo transcriptome assembly. Emerging long-read transcriptomic technology may substantially expand estimates of isoform and exon diversity but these technologies have not been applied to the developing human brain at scale. ${ }^{56,57}$ We also note that transcriptomic data is only partially predictive of protein levels and other factors, including channel transport and degradation, may influence the impact of isoforms on neuronal function. Comparing the human and mouse cortex data (Figs. 2, 4), it is possible that more substantial differences in gene and exon expression may be observed at earlier embryonic times in the mouse or with larger sample sizes. In addition, the use of bulk-tissue transcriptomic data limits our ability to assess how individual cell-types or cell-states contribute to the observed isoform trajectories. Technological and methodological advances may provide insights at cell-level resolution in the future. ${ }^{58}$

\section{Conclusion}

Dramatic differences in exon usage of SCN1A, SCN2A, SCN3A, and SCN8A observed in rodent brains also occur in the human developing cortex, beginning in mid-fetal development and continuing through childhood. These changes in splicing affect the biophysical properties of the encoded channels and are likely to contribute to differences in phenotype observed between individuals with different variants and across development.

\section{Acknowledgements}

This work was supported by funding provided by the Simons Foundation Autism Research Initiative (SFARI) grants 574598 (to S.J.S.), 647371 (to S.J.S.), 629287 (to K.J.B.), and 513133 (to K.J.B.), the National Institute for Mental Health (NIMH) grants: R01 MH111662 (to S.J.S.), U01 MH122681 (to S.J.S.), P50 MH106934 (to N.S.), R01 MH109904 (to N.S.), R01 MH110926 (to N.S.), and U01 MH116488 (to N.S.), the National Institute of Neurological Disorders and Stroke (NINDS) grant: R01 NS099099 (to J.L.R.R.), and the National Research Foundation of Korea: NRF2020R1C1C1003426 (to J.Y.A.) and NRF-2017M3C7A1026959 (to J.Y.A.).

\section{Author Contributions}

Experimental design, S.J.S.; Data generation, L.L., S.F.D., S.P., F.O.G., A.S., J.Y.A., and J.L.R.R.; Data processing, L.L., M.C.G., B.K.S., and D.M.W.; Data analysis, L.L., D.M.W., and S.J.S.; Statistical analysis, S.J.S.; Manuscript preparation, L.L., K.J.B., and S.J.S.

\section{Declaration of interests}


bioRxiv preprint doi: https://doi.org/10.1101/2020.11.18.389171; this version posted November 19,2020 . The copyright holder for this preprint (which was not certified by peer review) is the author/funder, who has granted bioRxiv a license to display the preprint in perpetuity. It is made available under aCC-BY-NC 4.0 International license.

427 J.L.R.R. is cofounder, stockholder, and currently on the scientific board of Neurona, a company 428 studying the potential therapeutic use of interneuron transplantation. 


\section{References}

430 1. Heyne HO, Singh T, Stamberger H, Abou Jamra R, Caglayan H, Craiu D, et al. De novo variants in neurodevelopmental disorders with epilepsy. Nat Genet [Internet]. 2018; :1. Available from: http://www.nature.com/articles/s41588-018-0143-7

2. Satterstrom FK, Kosmicki JA, Wang J, Breen MS, De Rubeis S, An J-Y, et al. Large-Scale

4. Catterall WAWA, Marban E, Catterall WAWA, Cestèle S, Catterall WAWA, Wood JN, et al.

9. Smith RS, Kenny CJ, Ganesh V, Jang A, Borges-Monroy R, Partlow JN, et al. Sodium

10. Berret E, Barron T, Xu J, Debner E, Kim EJ, Kim JH. Oligodendroglial excitability mediated

5. Bender KJ, Trussell LO. The physiology of the axon initial segment. Annu Rev Neurosci. 2012; 35(1):249-65.

6. Kole MHP, Stuart GJ. Signal processing in the axon initial segment. Neuron [Internet].

7. Spratt PWE, Ben-Shalom R, Keeshen CM, Burke KJJ, Clarkson RL, Sanders SJ, et al. The 2012; 73(2):235-47. Available from: http://dx.doi.org/10.1016/j.neuron.2012.01.007

8. Hu W, Tian C, Li T, Yang M, Hou H, Shu Y. Distinct contributions of $\mathrm{Na(v)1.6}$ and $\mathrm{Na}(\mathrm{v}) 1.2$ in action potential initiation and backpropagation. Nat Neurosci [Internet]. 2009; 12(8):996-1002. Available from: http://www.ncbi.nlm.nih.gov/pubmed/19633666 Channel SCN3A (Na(V)1.3) Regulation of Human Cerebral Cortical Folding and Oral Motor Development. Neuron. 2018; 99(5):905-913.e7. by glutamatergic inputs and Nav1.2 activation. Nat Commun [Internet]. 2017; 8(1). Available from: http://dx.doi.org/10.1038/s41467-017-00688-0

11. Brunklaus A, Du J, Steckler F, Ghanty II, Johannesen KM, Fenger CD, et al. Biological concepts in human sodium channel epilepsies and their relevance in clinical practice. Epilepsia. 2020; 61(3):387-99.

12. Kang HJ, Kawasawa Yl, Cheng F, Zhu Y, Xu X, Li M, et al. Spatio-temporal transcriptome of the human brain. Nature [Internet]. 2011; 478(7370):483-9. Available from:

http://www.ncbi.nlm.nih.gov/pubmed/22031440 
13. Wolff M, Johannesen KM, Hedrich UBS, Masnada S, Rubboli G, Gardella E, et al. Genetic and phenotypic heterogeneity suggest therapeutic implications in SCN2A-related disorders. Brain [Internet]. 2017; . Available from: https://academic.oup.com/brain/article-lookup/doi/10.1093/brain/awx054

14. Liao Y, Anttonen A-K, Liukkonen E, Gaily E, Maljevic S, Schubert S, et al. SCN2A mutation associated with neonatal epilepsy, late-onset episodic ataxia, myoclonus, and pain. Neurology. 2010; 75(16):1454-8.

16. Plummer NW, McBurney MW, Meisler MH. Alternative splicing of the sodium channel

15. Tian C, Wang K, Ke W, Guo H, Shu Y. Molecular identity of axonal sodium channels in human cortical pyramidal cells. Front Cell Neurosci [Internet]. 2014; 8(September):297. Available from: http://journal.frontiersin.org/article/10.3389/fncel.2014.00297/abstract

17. Gustafson TA, Clevinger EC, Neill TJO, Yarowskys PJ, Kruegerg BK. Mutually exclusive SCN8A predicts a truncated two-domain protein in fetal brain and non-neuronal cells. J Biol Chem. 1997; 272(38):24008-15. exon splicing of type III brain sodium channel alpha subunit RNA generates developmentally regulated isoforms in rat brain. J Biol Chem. 1993; 268(25):18648-53.

18. Zaman T, Helbig KL, Clatot J, Thompson CH, Kang SK, Stouffs K, et al. SCN3A-Related Neurodevelopmental Disorder: A Spectrum of Epilepsy and Brain Malformation. Ann Neurol. 2020; .

19. Zaman T, Helbig I, Božović IB, DeBrosse SD, Bergqvist AC, Wallis K, et al. Mutations in

20. Gazina E V, Richards KL, Mokhtar MBC, Thomas E a, Reid C a, Petrou S. Differential expression of exon 5 splice variants of sodium channel alpha subunit mRNAs in the developing mouse brain. Neuroscience [Internet]. 2010; 166(1):195-200. Available from: http://www.ncbi.nlm.nih.gov/pubmed/20006674

21. Tate SK, Depondt C, Sisodiya SM, Cavalleri GL, Schorge S, Soranzo N, et al. Genetic predictors of the maximum doses patients receive during clinical use of the anti-epileptic drugs carbamazepine and phenytoin. Proc Natl Acad Sci U S A. 2005; 102(15):5507-12.

22. Tate SK, Singh R, Hung CC, Tai JJ, Depondt C, Cavalleri GL, et al. A common polymorphism in the SCN1A gene associates with phenytoin serum levels at maintenance dose. Pharmacogenet Genomics. 2006; 16(10):721-6.

23. Thompson $\mathrm{CH}$, Ben-Shalom R, Bender KJ, George AL. Alternative splicing potentiates dysfunction of early-onset epileptic encephalopathy SCN2A variants. J Gen Physiol. 2020; 152(3):1-16.

24. Kasai N, Fukushima K, Ueki Y, Prasad S, Nosakowski J, Sugata KI, et al. Genomic structures of SCN2A and SCN3A - Candidate genes for deafness at the DFNA16 locus. Gene. 2001; 264(1):113-22.

25. Copley RR. Evolutionary convergence of alternative splicing in ion channels. Trends Genet. 2004; 20(4):171-6. 
26. Thompson $\mathrm{CH}$, Kahlig KM, George AL. SCN1A splice variants exhibit divergent sensitivity to commonly used antiepileptic drugs. Epilepsia. 2011; 52(5):1000-9.

27. Diss JKJ, Fraser SP, Djamgoz MBA. Voltage-gated Na+ channels: Multiplicity of expression, plasticity, functional implications and pathophysiological aspects. Eur Biophys J. 2004; 33(3):180-93.

28. Gazina E V., Leaw BTWW, Richards KL, Wimmer VC, Kim TH, Aumann TD, et al.

"Neonatal" Nav1.2 reduces neuronal excitability and affects seizure susceptibility and behaviour. Hum Mol Genet. 2015; 24(5):1457-68.

29. O'Brien JE, Drews VL, Jones JM, Dugas JC, Barres BA, Meisler MH. Rbfox proteins regulate alternative splicing of neuronal sodium channel SCN8A. Mol Cell Neurosci [Internet]. 2012; 49(2):120-6. Available from: http://dx.doi.org/10.1016/j.mcn.2011.10.005

30. Zubović L, Baralle M, Baralle FE. Mutually exclusive splicing regulates the Nav 1.6 sodium

31. Harrow J, Frankish A, Gonzalez JM, Tapanari E, Diekhans M, Kokocinski F, et al. GENCODE: the reference human genome annotation for The ENCODE Project. Genome

34. Dobin A, Davis CA, Schlesinger F, Drenkow J, Zaleski C, Jha S, et al. STAR: ultrafast Res [Internet]. 2012; 22(9):1760-74. Available from:

32. Werling DM, Pochareddy S, Choi J, An J-YY, Sheppard B, Peng M, et al. Whole-Genome and RNA Sequencing Reveal Variation and Transcriptomic Coordination in the Developing Human Prefrontal Cortex. Cell Rep. 2020; 31(1):107489.

33. MacLaren R, Radcliffe RA, Van Matre ET, Robertson CE, Ir D, Frank DN. The Acute Influence of Acid Suppression with Esomeprazole on Gastrointestinal Microbiota and Brain Gene Expression Profiles in a Murine Model of Restraint Stress. Neuroscience [Internet]. 2019; 398:206-17. Available from: https://doi.org/10.1016/j.neuroscience.2018.11.048

35. Anders S, Reyes A, Huber W. Detecting differential usage of exons from RNA-seq data.

36. Bedre R. reneshbedre/bioinfokit: Bioinformatics data analysis and visualization toolkit.

37. Karimzadeh M, Ernst C, Kundaje A, Hoffman MM. Umap and Bismap: quantifying genome

38. Wu J, Anczukow O, Krainer AR, Zhang MQ, Zhang C. OLego: fast and sensitive mapping of spliced mRNA-Seq reads using small seeds. Nucleic Acids Res. 2013; 41(10):5149-63. 
quantification of RNA splicing using LeafCutter. Nat Genet. 2018; 50(1):151-8.

546

547

548

549

550

551

552

553

554

555

556

557

558

559

560

561

562

563

564

565

566

567

568

569

570

571

572

573

574

575

576

577

578

579

580

581

582

40. An J-Y, Lin K, Zhu L, Werling DM, Dong S, Brand H, et al. Genome-wide de novo risk score implicates promoter variation in autism spectrum disorder. Science. 2018; 362(6420):eaat6576.

41. Ongen H, Buil A, Brown AA, Dermitzakis ET, Delaneau O. Fast and efficient QTL mapper for thousands of molecular phenotypes. Bioinformatics. 2016; 32(10):1479-85.

42. Benjamini Y, Hochberg Y. Controlling the False Discovery Rate: A Practical and Powerful Approach to Multiple Testing. J R Stat Soc Ser B. 1995; 57(1):289-300.

43. Nowakowski TJ, Bhaduri A, Pollen AA, Alvarado B, Mostajo-Radji MA, Di Lullo E, et al. Spatiotemporal gene expression trajectories reveal developmental hierarchies of the human cortex. Science [Internet]. 2017; 358(6368):1318-23. Available from: http://www.sciencemag.org/lookup/doi/10.1126/science.aap8809

44. Li M, Santpere G, Kawasawa YI, Evgrafov O V., Gulden FO, Pochareddy S, et al. Integrative functional genomic analysis of human brain development and neuropsychiatric risks. Science. 2018; 362(6420).

45. Tang L, Lu X, Tao Y, Zheng J, Zhao P, Li K, et al. SCN1A rs3812718 polymorphism and susceptibility to epilepsy with febrile seizures: a meta-analysis. Gene. 2014; 533(1):2631.

46. Wang ZJ, Chen J, Chen HL, Zhang LY, Xu D, Jiang WT. Association between SCN1A polymorphism rs3812718 and valproic acid resistance in epilepsy children: a casecontrol study and meta-analysis. Biosci Rep. 2018; 38(6).

47. The International League Against Epilepsy Consortium on Complex Epilepsies. Genomewide mega-analysis identifies 16 loci and highlights diverse biological mechanisms in the common epilepsies. Nat Commun. 2018; 9(1):5269.

48. Heinzen EL, Yoon W, Tate SK, Sen A, Wood NW, Sisodiya SM, et al. Nova2 interacts with a Cis-acting polymorphism to influence the proportions of drug-responsive splice variants of SCN1A. Am J Hum Genet. 2007; 80(5):876-83.

49. GTEx Consortium. Human genomics. The Genotype-Tissue Expression (GTEx) pilot analysis: multitissue gene regulation in humans. Science [Internet]. 2015; 348(6235):648-60. Available from: http://www.ncbi.nlm.nih.gov/pubmed/25954001

50. Jaganathan K, Kyriazopoulou Panagiotopoulou S, McRae JFJF, Darbandi SFSF, Knowles D, Li YIYI, et al. Predicting Splicing from Primary Sequence with Deep Learning. Cell [Internet]. 2019; 0(0):1-14. Available from: https://linkinghub.elsevier.com/retrieve/pii/S0092867418316295

51. Kim J, Hu C, Moufawad El Achkar C, Black LE, Douville J, Larson A, et al. PatientCustomized Oligonucleotide Therapy for a Rare Genetic Disease. N Engl J Med. 2019; 381(17):1644-52.

52. Finkel RS, Mercuri E, Darras BT, Connolly AM, Kuntz NL, Kirschner J, et al. Nusinersen 
versus Sham Control in Infantile-Onset Spinal Muscular Atrophy. N Engl J Med [Internet]. 2017/11/02. 2017; 377(18):1723-32. Available from: https://www.ncbi.nlm.nih.gov/pubmed/29091570

53. Berkovic SF, Grinton B, Dixon-Salazar T, Laughlin BL, Lubbers L, Milder J, et al. De novo variants in the alternative exon 5 of SCN8A cause epileptic encephalopathy. Genet Med. 2018; 20(2):275-81.

54. Sanders SJ, Campbell AJ, Cottrell JR, Moller RS, Wagner FF, Auldridge AL, et al. Progress in Understanding and Treating SCN2A-Mediated Disorders. Vol. 41, Trends in Neurosciences. 2018. p. 442-56.

55. Xu R, Thomas EA, Jenkins M, Gazina E V., Chiu C, Heron SE, et al. A childhood epilepsy mutation reveals a role for developmentally regulated splicing of a sodium channel. Mol Cell Neurosci. 2007; 35(2):292-301.

56. Anvar SY, Allard G, Tseng E, Sheynkman GM, de Klerk E, Vermaat M, et al. Full-length mRNA sequencing uncovers a widespread coupling between transcription initiation and mRNA processing. Genome Biol. 2018; 19(1):1-18.

57. Clark MB, Wrzesinski T, Garcia AB, Hall NAL, Kleinman JE, Hyde T, et al. Long-read sequencing reveals the complex splicing profile of the psychiatric risk gene CACNA1C in human brain. Mol Psychiatry [Internet]. 2020; 25(1):37-47. Available from: http://dx.doi.org/10.1038/s41380-019-0583-1

59. Quinlan AR, Hall IM. BEDTools: a flexible suite of utilities for comparing genomic

60. Patro R, Duggal G, Love MI, Irizarry RA, Kingsford C. Salmon provides fast and bias-aware 608 quantification of transcript expression. Nat Methods. 2017; 14(4):417-9. 